\title{
The Analysis Carbon Footprint of TDG Bamboo Laminated Column
}

\author{
Songkarn Kongsricharoen ${ }^{1}$ \\ ${ }^{* 1} \mathrm{~A}$ Ph.D. Student in the Engineering Law and Inspection \\ The program, Ramkhamhaeng University;
}

Asst. Prof. Dr. Waranon Kongsong ${ }^{2}$

${ }^{* 2}$ Assistant Professor in the Engineering Law and Inspection

Faculty of Engineering, Ramkhamhaeng University

ORCID: 0000-0003-2651-8476

Dr. Boontham Harnphanich ${ }^{3}$

${ }^{*}$ Special Lecturer in the Engineering Law and Inspection Faculty of Engineering, Ramkhamhaeng University

\begin{abstract}
From the global warming problem at present caused by many sources, building materials are another cause that directly and indirectly affects the environment. A carbon footprint is another way to measure the environmental impact of the product. In this paper, TDG bamboo in Thailand used for processing into the standardsized bamboo columns and analyzing the carbon footprint resulting from the production process. The strips of TDG bamboos glued together to the size $50 \times 50 \times 1000 \mathrm{~mm}$. The results have shown that transportation produces the highest carbon footprint approximate $0.0716 \mathrm{CO}_{2}$ ton compared to other processes.
\end{abstract}

Keywords-Dendrocalamus Gigantues; Carbon footprint ; TDG laminated column

\section{INTRODUCTION}

\section{A. Carbon footprint in Thailand}

Carbon footprint analysis of the product by calculating the number of greenhouse gases emitted from the production process In each type to calculate it in terms of carbon dioxide equivalent (tCO2e). The carbon footprint of Thailand compared with other countries around the world, not to higher, but when studying the statistics of the increased carbon dioxide in the graph shows a rapid increase.[1]

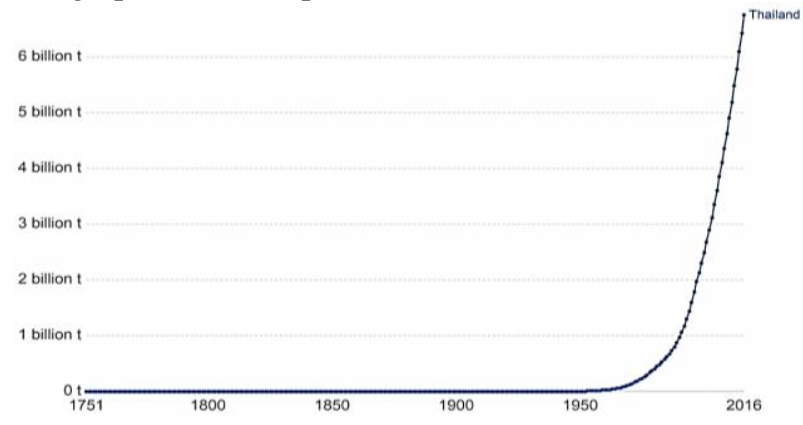

Fig 1 Carbon dioxide emissions in Thailand

In Thailand, 2017, carbon dioxide emissions per capita average of 3.90 tons of carbon dioxide per person, down

\author{
Assoc. Prof. Dr. Seree Tuprakay ${ }^{4}$ \\ ${ }^{* 4}$ Associate Professor in the Engineering Law and \\ Inspection Program, Faculty of Engineering, \\ Ramkhamhaeng University. \\ Dr. Chaleeporn Thammapornram ${ }^{5}$ \\ ${ }^{*}$ Bamboo Research center Director, the Engineering Law \\ and Inspection Program, Faculty of Engineering \\ Ramkhamhaeng University \\ ORCID: 0000-0003-2273-5473
}

Asst. Prof. Dr. Sirawan Ruangchuay Tuprakay ${ }^{6}$ ${ }^{*}$ Assistant Professor in Urban and Industry Environment Faculty of Science and Technology, Suan Dusit University

slightly from 2018, with average emissions level of 3.92 tons of carbon dioxide per person. Considering the last ten years found that per capita carbon dioxide emissions are likely to increase. [2] Carbon dioxide in the atmosphere caused by natural and human-made factors, such as deforestation, Residence, or agriculture. The most critical space probe that emits carbon dioxide into the atmosphere due to trees. The forest absorbed carbon dioxide into the atmosphere. Decline in forest area, As a result, the amount of carbon dioxide in the atmosphere increases. [3] Results of the study of the amount of oxygen, carbon dioxide by the IPCC (Climate Change Intergovernmental Agency) in the year 1980 shown that the amount of carbon dioxide generated from deforestation for use as urban or agricultural areas is estimated. $1.6 \mathrm{Gtc}$. Thailand, the decline of forests equal to 0.39 percent or $1,261,761$ rai. Ninety-eight hectares per year, an increase of population in the country on average 680,000 people a year that would show that. If the population increases by one person, forests decreased by 1.86 rai (average period of 56 years from 2504 to 2560. [4]

\section{B. Dendrocalamus Gigantues bamboo(TDG)}

Thailand is the country where most of the population is agriculture.Following the economic development plan of Thailand year, 2060-2021(BC.) which, focuses on restructuring the production of Thailand, changed from the agricultural sector to the industry sector.[5] Economic development bamboo production and manufacturing provides job opportunities in less developed countries that need social and economic sustainability. China, the world's largest bamboo producer, was valued at over 19.5 billion USD in 2012, employing over 7.5 million people. This serves as a model for other countries looking to develop a sustainable bamboo industry. [6]

Bamboo is sustainable materials because of once time; if we grow the bamboo, they keep growing without replanting until 60-130 years, depending on the species of bamboo.[7] Renewable resource - bamboo can be harvested in one to five years, depending on the species. In comparison, hardwoods like 
oak trees take at least forty years before they can be harvested. Over one million acres of forests are lost each week due to deforestation. As a substitute for hardwoods, bamboo offers a versatile solution. To use the bamboo for building nothing new for people in Thailand but to developing into the industrial process very low.[8][9][10]Bamboo absorbs greenhouse gases - bamboo sequesters carbon dioxide from the environment and produces $35 \%$ more oxygen than its equivalent size of trees. Large-scale bamboo plantations can become effective "carbon sinks" or areas designed to reduce $\mathrm{CO} 2$ from the atmosphere. When bamboo fibers are used to construct buildings, the carbon is sequestered (stored away) for the lifetime of that building.

In Thailand, bamboo growth everywhere in Thailand, but most growth in the north. The resource capacity of TDG bamboo Nan province the yield of bamboo 6-10 inches long 25-35 meters 120-150 culms/rai per year. The bamboo harvest from Nan's Bamboo Garden, which total of culms approximately 840,000-1,050,000 culm/years. The bamboo grows in the three types of forest. [11] The data from the Ministry of Natural and Environment Thailand.

1. Mixed forest with the density of bamboo approximately 37.511 grove /Rai or 424 culms/Rai

2. Dry evergreen forest with the density of bamboo approximately 7.34 grove /Rai or 88 culms/Rai

3. Evergreen forest with the density of bamboo approximately 6.1 grove /Rai or 76 culms/Rai

\section{Dendrocalamus Gigantues bamboo laminate (TDG)}

[11][12][13] First study the physical properties, mechanical properties of TDG bamboo, and has processed bamboo for construction by testing the standard of engineering. The research found that the compressive strength of the TDG bamboo laminated column size standard $50 \times 50 \times 200[14] \mathrm{mm}$ can be classified as a hardwood .The average results as shown in table 1

Table 1. Average of the test result of TDG bamboo laminated column

\begin{tabular}{cccccc}
\hline \multirow{2}{*}{ Type } & Weight & Density & Moisture & Load & Stress \\
\cline { 2 - 6 } & $\mathbf{g}$ & $\mathbf{g} / \mathbf{c m}^{\mathbf{3}}$ & $\mathbf{\%}$ & $\mathbf{k g f}$ & $\mathbf{k g} / \mathbf{c m}^{\mathbf{2}}$ \\
\hline MA1 & 299 & 0.60 & 21.20 & 13450.00 & 538.00 \\
MA2 & 336 & 0.67 & 7.10 & 15479.57 & 619.18 \\
MA3 & 335 & 0.67 & 26.30 & 13950.00 & 558.00 \\
\hline
\end{tabular}

The mechanical properties of bamboo are based on ASTM D143-09 [15] and Standard for the wood test in Thailand (DPT 1221-51). [16] The details of the specimen's size $63 \times 50 \times 50 \mathrm{~mm}$ with the test results range of the stress between $52-117 \mathrm{~kg} / \mathrm{cm}^{2}$. The bending strength of TDG laminated [11] Average of the modulus of elasticity; TDG beam coated with resin $270140.87 \mathrm{~kg} / \mathrm{cm}^{2}$, TDG beam without coated with resin $159457.74 \mathrm{~kg} / \mathrm{cm}^{2}$.From the test, results can be classified as a hardwood . From past research studies, it found that TDG bamboo has qualities that can be used to replace wood in the future. For TDG bamboo to be able to be environmentally friendly construction materials, this research has studied the carbon footprint of bamboo column production processes.

\section{RESEARCH OBJECTIVES}

The scope of a study; TDG bamboo used for experimental taken from Nan province, Tha Wang Pha at age 3 years. The TDG culms measured above 6 meters from the bottom culms and cut into 2 meters long set the code to 3 parts; bottom middle and top. In this paper, analysis of the carbon footprint from the production process of the standard bamboo column as shown in fig 1

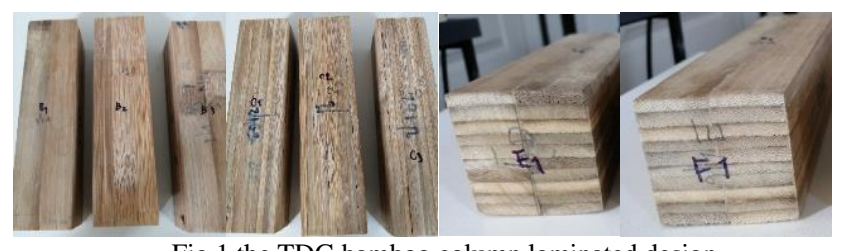

Fig 1 the TDG bamboo column laminated design

\section{MATERIALS AND METHODS}

In the study, the production process divided into 3 part as the following

\section{A. The circle of the process 1}

Begin with transportation and treatment of the bamboo, as shown in fig 2 .Transportation analysis the distance of traveling and gas that used during travel in both direction.

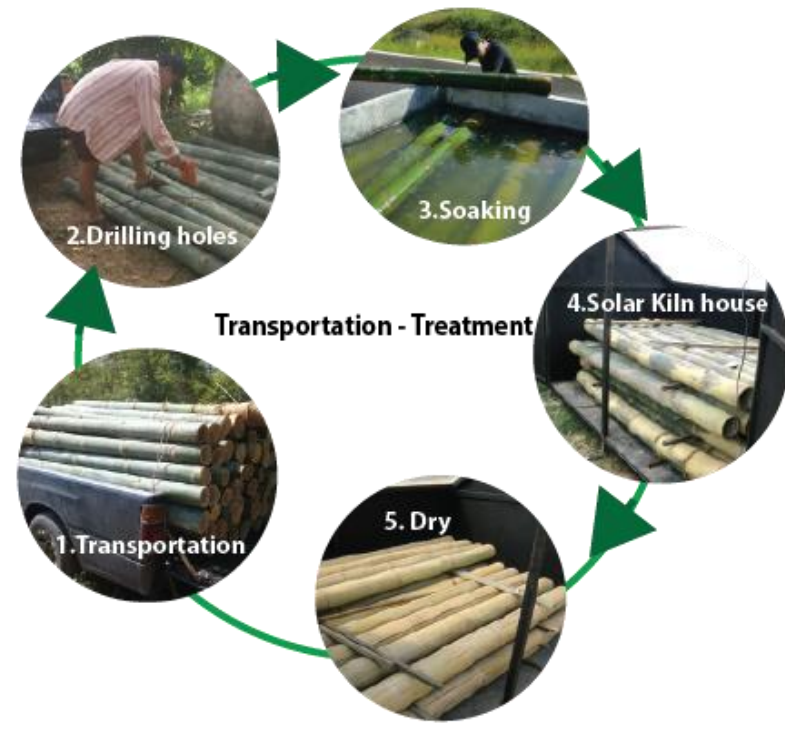

Fig 2. The circle of the process of production 1

B. The circle of process 2

Strips making process analysis any process as shown in fig 3 , which start from drawing the line, measurement, cut into strips size, cut the node, and planer. To analysis the strips maker involved with the part of bamboo in this study bamboo divided into three-part; bottom middle and top as shown in fig 3

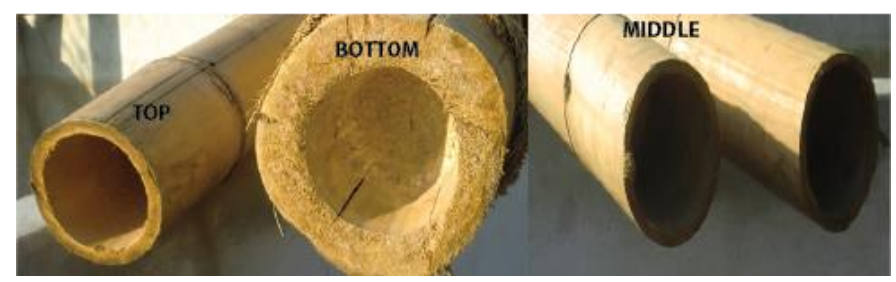

Fig 3 physical properties of the TDG bamboo 


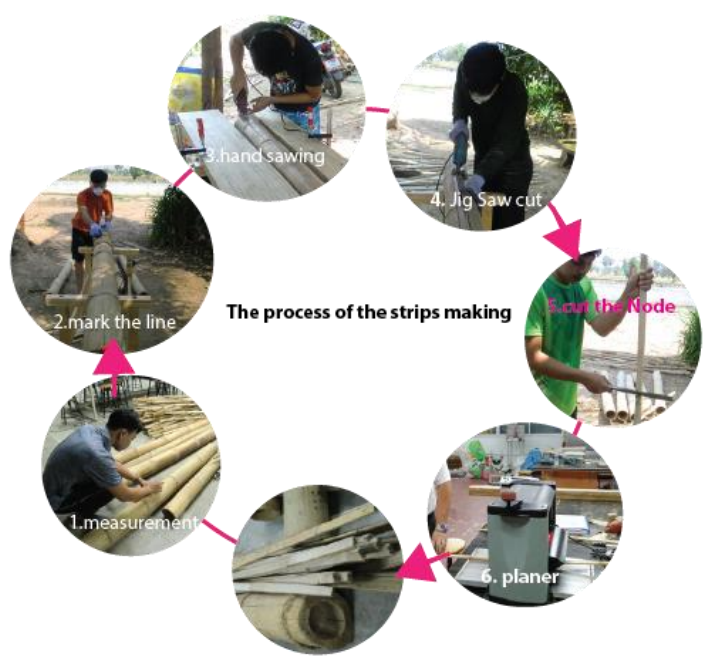

Fig 3. The circle of the process of production 2

\section{The circle of process 3}

TDG bamboo column forming process; glue the strip in a block and clamp more than 8 hours after that cut into the size and planer as shown in fig 4

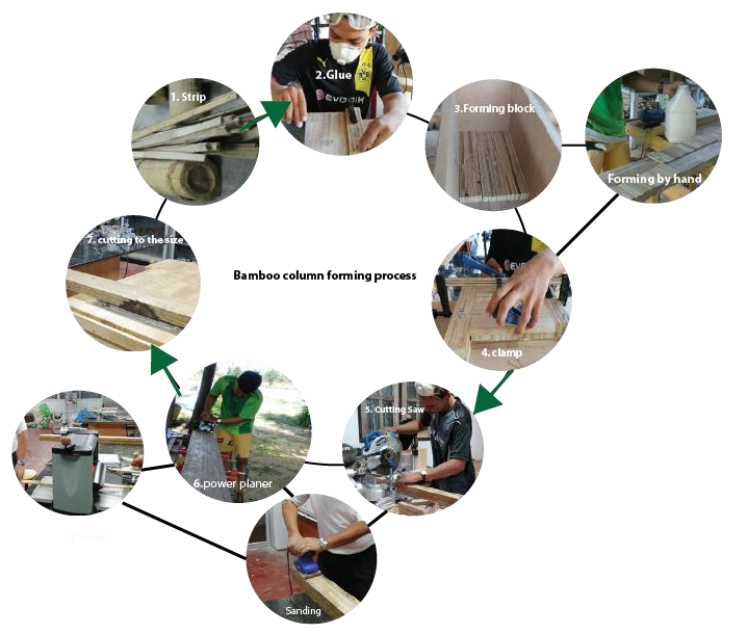

Fig 4. The circle of the process of production 3

\section{D. the basic Information for calculation}

The basic information for calculating the carbon footprint of the column laminated in this paper analysis from transportation to construct the column by analysis different part of the selection bamboo as shown in fig 1

\begin{tabular}{|c|}
\hline $\begin{array}{c}\text { Production Process part selection } \\
\text { at the bottom }\end{array}$ \\
\hline $\begin{array}{c}\text { Production Process part selection } \\
\text { Production Process part selection } \\
\text { at the top }\end{array}$ \\
\hline \begin{tabular}{c} 
aton \\
\hline
\end{tabular}
\end{tabular}

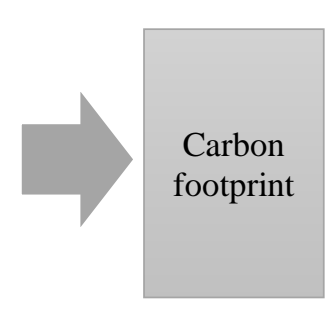

Fig 5. The basic calculation different part of a bamboo

\section{EXPERIMENT RESULTS AND DISCUSSION}

The carbon footprint analysis of the circle of the process production 1 as the following

\section{A. transportation}

Transportation process for calculating the load and distance in this research used two truck to load the TDG bamboo 100 culms which the detail of load as shown in table 1

Table 1 detail of trip Load

\begin{tabular}{cccc} 
& Transportation (material collection) & Tool & Total \\
\hline \multirow{4}{*}{ Trip } & Transportation & & No. \\
& Bangkok - Nan (0\% Load) & Truck & 2 \\
& Nan - Ta Wong Pa (0\% Load) & Truck & 2 \\
\multirow{3}{*}{ Return } & Ta Wong Pa - Doi Tiw (0\% Load) & Truck & 2 \\
& Doi Tiw - Ta Wong Pa (100\% Load) & Truck & 2 \\
& Ta Wong Pa - Nan (100\% Load) & Truck & 2 \\
& Nan - Buriram (100\% Load) & Truck & 2 \\
\hline
\end{tabular}

The results of carbon footprint each load depending on the distance of travel for this total research distance ;one truck $1625.3 \mathrm{~km}$,two truck $3250.6 \mathrm{~km}$ with produced the carbon approximately 0.7586 ton the result as shown in table 2

Table 2 carbon footprint calculation

\begin{tabular}{|l|c|c|c|c|}
\hline Transportation (material collection) & Distance & Total & (kgCO2eq/unit) & CO2 \\
\hline Transportation & $\mathrm{km}$ & $\mathrm{km}$ & $\mathrm{tkm}$ & $\mathrm{tkm}$ \\
\hline Bangkok - Nan (0\% Load) & 672 & 1344 & 0.3133 & 421.08 \\
\hline Nan - Ta Wong Pa (0\% Load) & 50 & 100 & 0.3133 & 31.33 \\
\hline Ta Wong Pa - Doi Tiw (0\% Load) & 24.8 & 49.6 & 0.3133 & 15.54 \\
\hline Doi Tiw - Ta Wong Pa (100 \% Load) & 24.8 & 49.6 & 0.1411 & 7 \\
\hline Ta Wong Pa - Nan (100\% Load) & 50 & 100 & 0.1411 & 14.11 \\
\hline Nan - Buriram (100\% Load) & 803.7 & 1607.4 & 0.1411 & 226.8 \\
\hline Total & $\mathbf{1 6 2 5 . 3}$ & $\mathbf{3 2 5 0 . 6}$ & $\mathbf{1 . 3 6 3 2}$ & $\mathbf{7 1 5 . 8 6}$ \\
\hline & & & ton & 0.71586 \\
\hline
\end{tabular}

B.Preservation and Dry

The analysis in this process depending on the electric that used for drying the bamboo and the water that used for preservation The total carbon produced in this process approximately 0.002435 ton as shown in table 3

Table 3 carbon footprint calculation

\begin{tabular}{lccr}
\hline \multicolumn{1}{c}{ Tool } & size & factor & \multicolumn{1}{c}{ CO2 } \\
\hline Tank concrete & 7.5 & 0.3238 & 2.4285 \\
Timbor & 0 & 0 & 0 \\
Solar Kiln House & 0 & 0 & 0 \\
fan & 0.01 & 0.6933 & 0.006933 \\
\hline & & Total & 2.435433 \\
\hline & & ton & 0.002435 \\
\hline
\end{tabular}

The total carbon footprint that made from circle 1 approximately 0.718295 ton

The carbon footprint analysis of the circle of the process production 2 .This process of strip making depending on the size of the bamboo and the electric tool used during the process .In this research, the factor of parts such as the bottom, middle, and top. The results as following

A. Basic information

The strip makes depending on the physical property;TDG bamboo at the bottom have the most significant size in both circumference or thickness as shown in table 4 and fig 6 


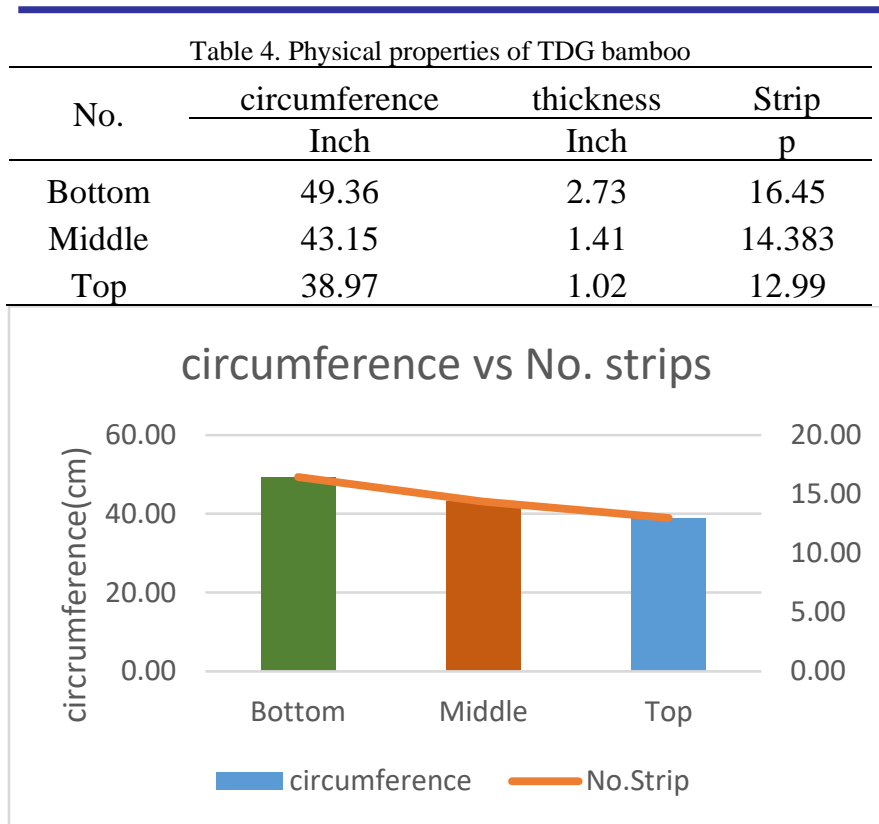

Fig 6. Circumference vs. Number of the strip

The physical property directly affects the carbon footprint during the process because the thickness of the bamboo is hard to cut the process used more time and tool to finish.as the following carbon footprint calculation

\section{B. strip making with the bottom part}

The strip making at the bottom part produced the carbon footprint approximately 0.0004 ton

Table 5 calculation the carbon footprint during the strips making

\begin{tabular}{|l|l|c|c|c|r|}
\hline Strip making process & \multicolumn{1}{|c}{ Tool } & Time & Kwh & Factor & CO2 \\
\hline Mark the line & Ruler,Pencil & 0.1 & 0 & 0.6933 & 0 \\
\hline Mark the line & String line & 0.05 & 0 & 0.6933 & 0 \\
\hline Cut along the line & Rotarazer Sar & 0.15 & 0.06 & 0.6933 & 0.041598 \\
\hline Cut along the line & Jig Saw & 0.15 & 0.075 & 0.6933 & 0.051998 \\
\hline cut the node & Knife & 0.05 & 0 & 0.6933 & 0 \\
\hline & Jig Saw & 0.1 & 0.05 & 0.6933 & 0.034665 \\
\hline Planer & Planer & 0.15 & 0.27 & 0.6933 & 0.187191 \\
\hline & Power Planer & 0.15 & 0.087 & 0.6933 & 0.060317 \\
\hline & & & & & $\mathbf{0 . 3 7 5 8}$ \\
\hline & & 0.9 & T & Total & $\mathbf{0 . 0 0 0 4}$ \\
\hline
\end{tabular}

\section{C. strip making with the middle part}

The strip making at the middle part produced the carbon footprint approximately 0.0004 ton

Table 5 calculation the carbon footprint during the strips making

\begin{tabular}{|l|l|c|c|c|r|}
\hline Strip making process & \multicolumn{1}{|c}{ Tool } & Time & Kwh & Factor & CO2 \\
\hline Mark the line & Ruler,Pencil & 0.1 & 0 & 0.6933 & 0 \\
\hline Mark the line & String line & 0.05 & 0 & 0.6933 & 0 \\
\hline Cut along the line & Rotarazer Sa & 0.15 & 0.06 & 0.6933 & 0.041598 \\
\hline Cut along the line & Jig Saw & 0.15 & 0.075 & 0.6933 & 0.051998 \\
\hline cut the node & Knife & 0.05 & 0 & 0.6933 & 0 \\
\hline & Jig Saw & 0.1 & 0.05 & 0.6933 & 0.034665 \\
\hline Planer & Planer & 0.15 & 0.27 & 0.6933 & 0.187191 \\
\hline & Power Planer & 0.15 & 0.087 & 0.6933 & 0.060317 \\
\hline & & & & & $\mathbf{0 . 3 7 5 8}$ \\
\hline & & 0.9 & T & Total & $\mathbf{0 . 0 0 0 4}$ \\
\hline
\end{tabular}

D. strip making with the top part

The strip making at the top part produced the carbon footprint approximately 0.0003 ton

Table 5 calculation the carbon footprint during the strips making

\begin{tabular}{|l|l|c|c|c|r|}
\hline Strip making process & \multicolumn{1}{|c}{ Tool } & Time & Kwh & Factor & CO2 \\
\hline Mark the line & Ruler,Pencil & 0.1 & 0 & 0.6933 & 0 \\
\hline Mark the line & String line & 0.05 & 0 & 0.6933 & 0 \\
\hline Cut along the line & Rotarazer Sar & 0.15 & 0 & 0.6933 & 0 \\
\hline Cut along the line & Jig Saw & 0.15 & 0.075 & 0.6933 & 0.051998 \\
\hline cut the node & Knife & 0.05 & 0 & 0.6933 & 0 \\
\hline & Jig Saw & 0.1 & 0.05 & 0.6933 & 0.034665 \\
\hline Planer & Planer & 0.15 & 0.27 & 0.6933 & 0.187191 \\
\hline & Power Planer & 0.15 & 0.087 & 0.6933 & 0.060317 \\
\hline & & & & & $\mathbf{0 . 3 3 4 2}$ \\
\hline
\end{tabular}

E. Comparison of bamboo production processes

At the bottom part and middle part produced the carbon credit more than the top part because the thickness of the bamboo of both locations very hard the cut used more tool and time to produced .The result, as shown in fig 7 .

\section{Carbon footprint of strip making}

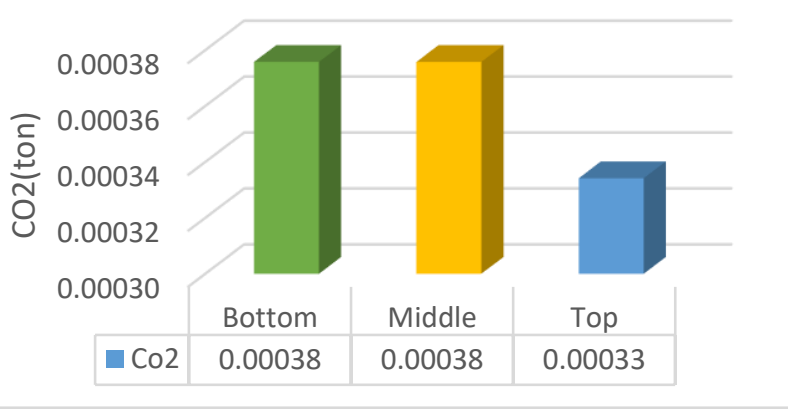

Fig 6. Comparison of bamboo production processes of the strips

The carbon footprint analysis of the circle of the process production 3.The bamboo column is a forming process; this process that affects carbon footprint while using the glue and electrical tool for cutting and sanding the columns. Following the results of the test

A. Glue weight

For the carbon footprint of forming the column, the critical factor as glue weight. The results show that the top part used more glue than another part. It applied more strip that other parts because of more glue to the adhesive. The results as shown in fig 7

\section{Glue Weight}

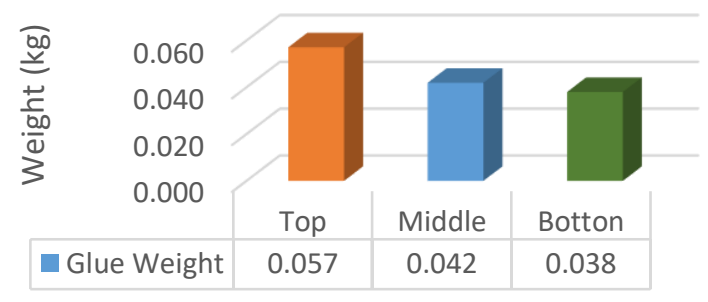

Fig 7. Glue weight different part 
This process, the strip glued together with clamp compresses the column for more than 8 hours. In this process, only glue causes carbon during the process. The results as shown in table 6

Table 6 calculation the carbon footprint during the forming process

\begin{tabular}{|c|c|c|c|c|c|}
\hline Forming the column & glue weight & total & factor & CO2 & ton \\
\hline top & 0.10 & 0.057 & 1.166 & 0.066585 & $6.65847 \mathrm{E}-05$ \\
\hline middle & 0.15 & 0.042 & 1.166 & 0.048911 & $4.89106 \mathrm{E}-05$ \\
\hline bottom & 0.20 & 0.038 & 1.166 & 0.044308 & $4.43080 \mathrm{E}-05$ \\
\hline
\end{tabular}

The comparison of the forming process different part as shown in fig 8 shown that the glue that used for top part more than Other parts cause produced more carbon credit.

\section{Carbon footprint}

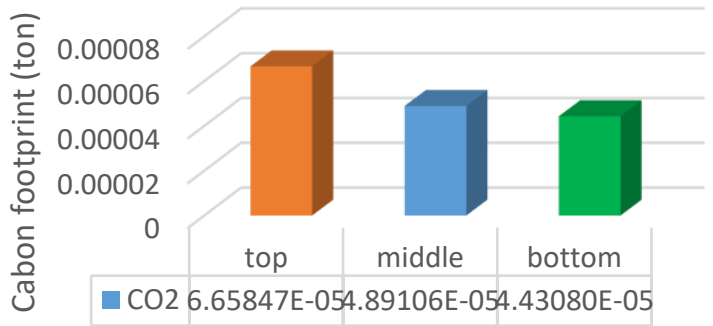

Fig 8. Carbon footprint during the forming process

\section{CONCLUSION}

For the analysis of the carbon credit that making the TDG laminated column from the results shown that the most significant producer of the carbon footprint is transportation material. The results, as shown in fig 9 .

Carbonfootprint

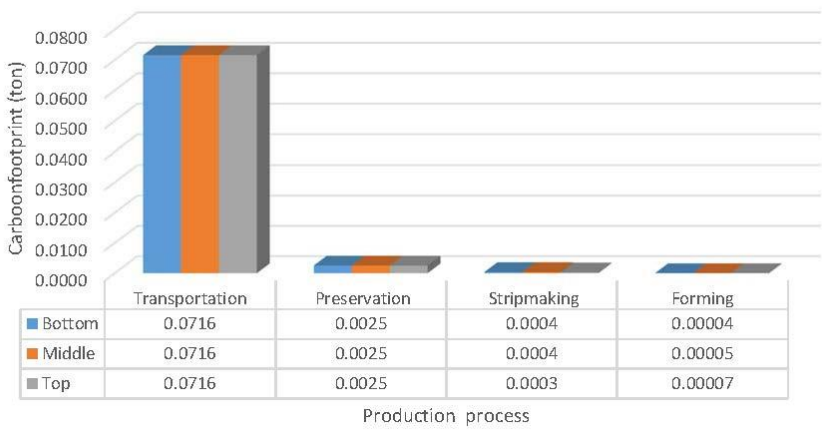

Fig 9. Comparison of Carbon footprint

The carbon footprint that produced during made the TDG bamboo column laminated approximate 0.074 tons per size $2 \times 2$ inch long 1 meter, which can reduce the carbon credit by used the local bamboo.

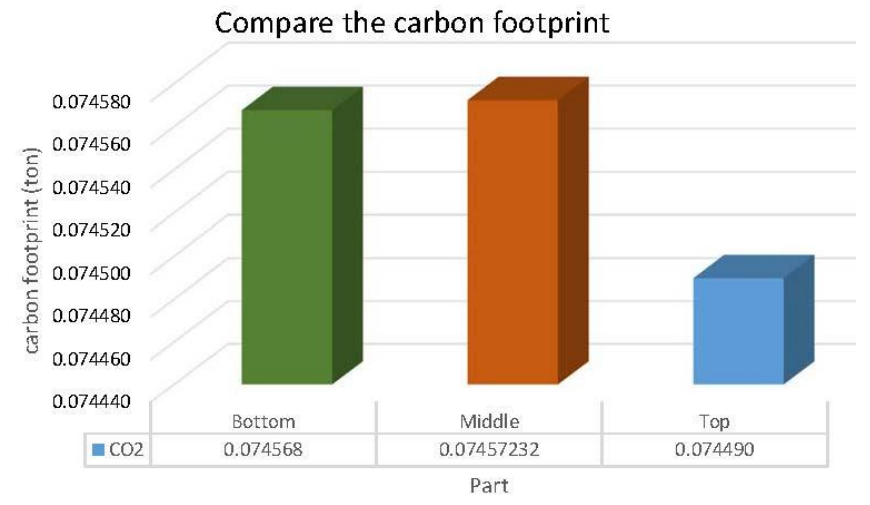

Fig 10. Comparison of Carbon footprint

\section{REFERENCES}

[1] GCP, G. c. (2019). Carbon Dioxide Information Analysis. USA: Carbon Dioxide in formation Analysis Center(CDIAC).

[2] Office Of Natural Resources and Environmental Policy and Planning (2019, January 9). Retrieved from http://www.onep.go.th/

[3] IPCC. (2019, January 13). Intergovernmental panel on climate change Retrieved from https://archive.ipcc.ch/

[4] Department of Forestry. (2561). The situation of Thai forests. Bangkok: Planners and Information Department of Forestry.

[5] Thammapornram, C. (2019, January 16). Megabamtech1212. Retrieved from megabamtech1212: http://megabamtech1212.com/elementor$1376 /$

[6] Sueb Nakhasathien Foundation (2018). Forest situation in Thailand. Bangkok: Department of Forestry and Faculty of Forestry, Kasetsart University

[7] Chaleeporn Thammapornram, Waranon Kongsong,Vorasun Buranakarn,effecting Factors of mechanical Properties of Thai Denrocalamus Gigantues Bamboo,International Journal of Civil Engineering and Technology (IJCIET) 9(13),2018,pp. 1457-1467

[8] Thamapornram C, Kongsong, \& Buranakarn V (2018). Thai Dendrocalamus Giganteus .Science, Technology, and Architecture. ESTCON Thailand

[9] Escamilla, E., \& Habert, G. (2014). Environment impacts of bamboobased construction materials representing global production diversity Journal of Cleaner Production diversity , 117-127

[10] Thammapornram C, (2018). The Innovation of Dendrocalamus Giganteus bamboo beam, PhD.dissertation of Engineering Law and Inspection: Faculty of Engineering Ramkhamhaeng University

[11] Kongsricharorn S, (2019). The Innovation of Dendrocalamus Giganteus bamboo Columns, PhD.dissertation of Engineering Law and Inspection: Faculty of Engineering Ramkhamhaeng University

[12] Kongsricharoen, S., Kongsong, W., Tuprakay, S., Tuprakay, S., \& Thammapornram, C. (2019). Analysis of the shear strength of Thai Dendrocalamus Gigantues (TDG) lamented bamboo by the factor of glue and location of the strips. International Journal of Civil Engineering and Technology (IJCIET), 253-262ASTM D143-09. (2009). Standard test method for small clear specimens of timber. West Conshohocken ,PA,USA: ASTM international

[13] Kongsricharoen, S., Kongsong, W., Tuprakay, S., Tuprakay, S., \& Thammapornram, C. (2019). Column design Compression performance of Thai Dendrocalamus Gigantues laminated bamboo. lamented bamboo by the factor of glue and location of the strips. International Journal of Civil Engineering and Technology (IJCIET), 263-274

[14] DPT 1222-51. (2551). Standards Test for compressive strength of wood Thailand: The Bureau of Building Inspection and Control Department of Public Works and Town \& Country planning

[15] ASTM D143-09. (2009). Standard test method for small clear specimens of timber. West Conshohocken ,PA,USA: ASTM international

[16] DPT 1226-51. (2551). Standards Test Method for the shear test of wood parallel to Grain. Thailand: The Bureau of Building Inspection and Control Department of Public Works and Town \& Country planning 